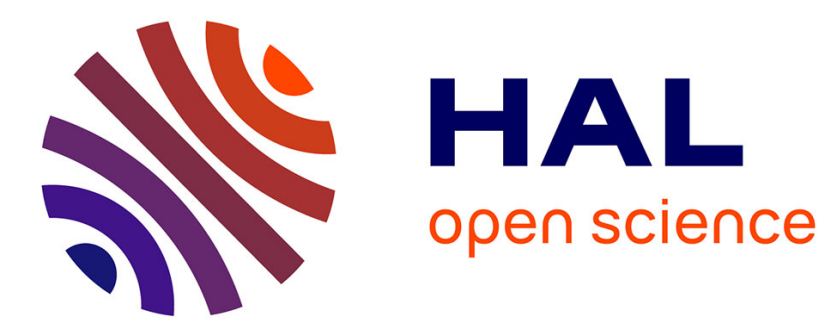

\title{
IgG4-positive plasma cell infiltration in explanted livers for primary sclerosing cholangitis
}

\author{
Yoh Zen, Alberto Quaglia, Bernard Portmann
}

\section{To cite this version:}

Yoh Zen, Alberto Quaglia, Bernard Portmann. IgG4-positive plasma cell infiltration in explanted livers for primary sclerosing cholangitis. Histopathology, 2011, 58 (3), pp.414. 10.1111/j.13652559.2011.03763.x . hal-00616542

\section{HAL Id: hal-00616542 \\ https://hal.science/hal-00616542}

Submitted on 23 Aug 2011

HAL is a multi-disciplinary open access archive for the deposit and dissemination of scientific research documents, whether they are published or not. The documents may come from teaching and research institutions in France or abroad, or from public or private research centers.
L'archive ouverte pluridisciplinaire HAL, est destinée au dépôt et à la diffusion de documents scientifiques de niveau recherche, publiés ou non, émanant des établissements d'enseignement et de recherche français ou étrangers, des laboratoires publics ou privés. 


\section{Histopathology}

\section{IgG4-positive plasma cell infiltration in explanted livers for primary sclerosing cholangitis}

\begin{tabular}{|r|l|}
\hline Journal: & Histopathology \\
\hline Manuscript ID: & HISTOP-09-09-0508.R2 \\
\hline Manuscript Type: & Original Article \\
\hline Author: & 26-Mar-2010 \\
\hline Complete List of Authors: & $\begin{array}{l}\text { Zen, Yoh; King's College Hospital, Institute of Liver Studies } \\
\text { Quaglia, Alberto; King's College Hospital, Institute of Liver Studies } \\
\text { Portmann, Bernard; King's College Hospital, Institute of Liver } \\
\text { Studies }\end{array}$ \\
\hline Keywords: & $\begin{array}{l}\text { IgG4, sclerosing cholangitis, autoimmune pancreatitis, } \\
\text { transplantation }\end{array}$ \\
\hline
\end{tabular}

\section{$\checkmark$ ScholaroNE" \\ Manuscript Central}


Title page

\section{IgG4-positive plasma cell infiltration in explanted livers for primary sclerosing cholangitis}

Yoh Zen, ${ }^{1}$ Alberto Quaglia, ${ }^{1}$ Bernard Portmann ${ }^{1}$

${ }^{1}$ Institute of Liver Studies, King's College Hospital, London, UK.

Address correspondence to: Yoh Zen, MD; Institute of Liver Studies, King's College Hospital, Denmark Hill, London SE5 9RS, UK; Tel: +44 (0)20 3299 3734; Fax: +44 (0)20 3299 3125; E-mail: yoh.zen@kcl.ac.uk

Running title: IgG4-positive cells in PSC

Keywords: IgG4, sclerosing cholangitis, autoimmune pancreatitis, transplantation

Abbreviations: PSC, primary sclerosing cholangitis; HPF, high power field. 


\begin{abstract}
Aims: To explore whether IgG4-related sclerosing cholangitis (IgG4-SC) contributes to end-stage primary sclerosing cholangitis (PSC) in UK.

Methods and Results: This study consisted of 41 patients who underwent liver transplantation for advanced PSC. Explanted livers were histologically examined with an emphasis on IgG4-positive plasma cell infiltration. Thirty-nine cases (95\%) had minimal or mild infiltration of IgG4-positive plasma cells ( $\leq 30$ cells/high power field). In contrast, two cases $(5 \%)$ showed plasma cell IgG4-positivity in more than 100 cells/high power field. IgG4-positive plasma cells were preferentially accumulated in (xantho)granulomatous tissue within large bile ducts. Except for the presence of IgG4-positive plasma cells there was no significant histological difference between IgG4-positive and negative cases. Both showed sclerosing cholangitis with bile duct erosion and xanthogranulomatous reaction more in keeping with PSC than typical IgG4-SC. Clinically the 2 patients differed from typical IgG4-related disease, in that both had associated ulcerative colitis, and one of them was younger than expected for IgG4-SC (28-year-old).

Conclusions: No classical IgG4-SC could be identified in patients explanted for PSC. The 2 cases identified with numerous IgG4-positive plasma cells suggest a superimposed immune mechanism of uncertain nature. A prospective study is needed to assess whether such cases will be steroid-sensitive.
\end{abstract}




\section{Introduction}

Recently, immunoglobulin G4 (IgG4)-related diseases have been the object of great attention. ${ }^{1,2}$ In 2001, Hamano et al. first reported that patients with sclerosing pancreatitis, also called autoimmune pancreatitis, have high serum IgG4 concentrations. ${ }^{3}$ Subsequent studies showed the presence of numerous IgG4-positive plasma cells in affected pancreatic tissue. ${ }^{4-6}$ Autoimmune pancreatitis is commonly associated with sclerosing cholangitis, so-called IgG4-related sclerosing cholangitis (IgG4-SC) or IgG4-associated cholangitis (IAC). ${ }^{1}$ IgG4-SC most often affects the intra-pancreatic bile duct but can occur at any level of the biliary tract. ${ }^{7}$ IgG4-SC may be difficult to differentiate from primary sclerosing cholangitis (PSC) on the basis of clinical and imaging features, especially when there is no associated pancreatitis. ${ }^{8}$ However, the distinction seems important, because response to steroid therapy may differ in IgG4-SC and PSC. ${ }^{9,10}$ Until now, there have been a few case report of steroid-sensitive PSC, ${ }^{11}$ although children presenting with autoimmune features have shown a good response in early stage of the disease. ${ }^{12}$

Mendes et al. ${ }^{13}$ reported that $9 \%$ of patients with PSC were found to have high serum IgG4 concentrations. However, it is still unknown whether or not cholangitis in those cases are IgG4-SC because of lacking of histological examination. IgG4 concentrations can be elevated in patients with other disorders such as allergic diseases. ${ }^{14} \mathrm{PSC}$ and $\mathrm{IgG} 4-\mathrm{SC}$ have been shown to have different histological characteristics. ${ }^{15}$ The number of IgG4-positive plasma cells was most important for this discrimination, although distribution or nature of the cholangitis was also different between those two sub-groups of cholangitis. Histological examination seems more useful than serological examination to differentiate PSC from IgG4-SC. 
We have reviewed a series of livers removed at transplantation for PSC. The aim is to detect whether patients with IgG4-SC might have been included in patients transplanted for PSC.

\section{Patients and Methods}

\section{Patients}

The 41 patients with PSC were selected from the histopathology files of the Institute of Liver Studies, King's College Hospital, London. All underwent liver transplantation from December 1997 to March 2003. Average age at the time of transplantation was 48 years (range 19 to 69). Male/female ratio was 24/17. No patients had any surgical treatments for hepatobiliary and pancreatic diseases before the transplantation.

\section{Clinical features}

Clinical records were available for all patients and reviewed for having or not inflammatory bowel diseases (ulcerative colitis or Crohn's disease). In addition, the medical histories were examined for potential IgG4-related diseases such as autoimmune pancreatitis, sclerosing sialadenitis, pulmonary pseudotumour and retroperitoneal fibrosis on clinical records and imaging. Before transplantation serum values of total bilirubin, globulin, aspartate aminotransferase (AST), alanine aminotransferase (ALT), alkaline phosphatase (ALP), $\gamma$-glutamyl transpeptidase ( $\gamma$-GTP), eosinophil count, $\operatorname{IgG}, \operatorname{IgA}$, IgM, anti-nuclear antibody (ANA), and anti-neutrophilic cytoplasmic antibody (ANCA) were available. 


\section{Histological examinations}

After macroscopic examination of explanted livers, tissue blocks were sampled from intrahepatic large bile ducts, peripheral portal tracts, and liver parenchyma. Samples were fixed in neutral formalin, and embedded in paraffin. Sections $(4 \mu \mathrm{m})$ were cut from each paraffin block, and stained with haematoxylin \& eosin (H\&E), Azan-Mallory, Orcein, PAS after diastase digestion, reticulin, or elastica van Gieson (EvG) and additional sections were saved for immunohistochemistry. The following histological features were assessed on the most inflamed intrahepatic large bile duct or hepatic duct: inflammatory cell infiltration (-, absent or minimal; 1+, mild; $2+$, moderate; $3+$, severe), lymphoid follicle with germinal center (-, absent; +, present), phlebitis (-, absent; + , present), eosinophil infiltration $(-$ or + for $\leq 5$ or $>5$ cells/high power field [HPF: 10× eyepiece and 40× lens], respectively), perineural inflammation (-, absent; +, present), and Russell body (-, absent; +, present). The degree of portal inflammation was semi-quantitatively evaluated $(1+$, mild; $2+$, moderate; $3+$, severe). Severe portal inflammation was considered when associated with obvious interface activity, and moderate portal inflammation was defined as portal inflammatory infiltrate with occasional lymphoid aggregates. Mild portal inflammation was defined as mild lymphocytic infiltrates without lymphoid aggregates.

\section{Immunohistochemistry}

In each case representative blocks including intrahepatic large bile ducts or hepatic ducts were chosen for immunohistochemistry. Immunostaining of IgG4 was performed using a mouse monoclonal antibody against human IgG4 (ZYMED Laboratory Inc., San Francisco, CA, 
USA). Deparaffinized sections were microwaved in ethylenediaminetetraacetic acid (EDTA) buffer ( $\mathrm{pH}$ 8.0) for $20 \mathrm{~min}$. After blocking the endogenous peroxidase, the sections were incubated in normal goat serum for $20 \mathrm{~min}$, and then incubated for 1 hour at the room temperature with the primary antibody. After washing, these sections were incubated for 1 hour at room temperature with goat anti-mouse immunoglobulins, which were conjugated with peroxidase labelled polymer (Envision+, Dako Cytomation, Glostrup, Denmark). 3,3'-Diaminobenzidine tetrahydrochloride (DAB) was used as the chromogen, followed by light counterstaining with haematoxylin. A specimen of lymph node was used as a positive control. IgG4-positive plasma cells were counted in 3 different HPFs with intense inflammation around the large bile ducts and the average number was calculated in each case. The ratio (percentage) of IgG4-positive/total plasma cells was examined using the number of plasma cells per HPF counted on H\&E sections.

\section{Statistics}

A statistical analysis was performed using the Mann-Whitney U test to analyze variables. A probability of $\mathrm{p}<0.05$ was considered to be statistically significant.

\section{Results}

\section{Pathological features of explanted livers}

Livers were cirrhotic in 32 patients, pre-cirrhotic in 9 patients. Five cases had intrahepatic stones. Histologically, portal tracts were fibrously enlarged associated with fibrous septa. Regenerative nodules were irregular in shape, and hepatocytes adjacent to fibrous septa 
showed ballooning with or without Mallory bodies and prominent deposits of orcein-positive copper-associated granules in every case. Those features were consistent with chronic cholestatic liver disease.

All cases showed sclerosing inflammation around intrahepatic large bile ducts or hepatic ducts to variable degrees. At some sites bile ducts were completely occluded by fibrous tissue. Bile ducts showing erosions were associated with intraluminal proliferation of xanthogranulomatous tissue. Two cases showed biliary epithelial dysplasia (biliary intraepithelial neoplasia: BilIN). Within peripheral portal tracts, bile duct injury, periductal fibrosis and variable degree of ductopenia were noted. Histological features were consistent with PSC. Three cases were associated with intrahepatic cholangiocarcinoma (moderately differentiated adenocarcinoma). An additional case was complicated by a moderately differentiated hepatocellular carcinoma. A pseudotumorous appearance of the sclerosing inflammatory process (inflammatory pseudotumour) was not observed.

\section{Classification based on the degree of IgG4-positive cell infiltration}

Based on findings of IgG4 immunostaining, the 41 cases could be clearly classified into 2 groups (Figure 1). Thirty-nine cases (95\%) were associated with less than 30 IgG4-positive plasma cells/HPF around the inflamed large bile ducts ( $\leq 3$ cells/HPF in 20 cases, 4-10 cells/HPF in 9 cases, and 11-30 cells/HPF in 10 cases) (Figure 2). The remaining two cases (5\%) had severe infiltration (134 and 156 cells/HPF) of IgG4-positive cells (Figure 3). In both cases positive cells were mainly observed in large portal tracts with a preferential accumulation in xanthogranulomatous areas within large bile ducts (Figure 3). One of two cases also had 12 
IgG4-positive plasma cells/HPF in peripheral portal tracts (Figure 4), whereas the other case showed only 3 positive cells similar to that observed in the first group (average, 1 positive cell/HPF; range, 0-8 cells/HPF). Based on the fact that more than 50 IgG4-positive plasma cells/HPF are usually identified in surgical specimens of IgG4-related diseases, ${ }^{16,17}$ PSC could be classified into cases with numerous IgG4-positive plasma cells designated as IgG4-positive PSC ( 2 cases) and IgG4-negative PSC (39 cases).

As shown in Table 1, the number of plasma cells and the ratio of IgG4-positive/total plasma cells around the large bile ducts in IgG4-positive PSC were significantly higher than those in IgG4-negative cases.

\section{Comparison of pathological features between IgG4-positive and -negative groups}

As shown in Table 2, no significant histological differences were identified between the two groups. Both showed bile duct erosion with xanthogranulomatous reaction. Inflammatory changes were more pronounced around the luminal side compared to bile duct wall or periductal connective tissue. Similar to the IgG4-negative cases, IgG4-positive PSC showed periductal lamellar fibrosis or ductopenia in small portal tracts at the periphery. Phlebitis was identified in 50\% (1/2) of IgG4-positive and 49\% (19/39) of IgG4-negative cases. However, they were different from obliterative phlebitis typically observed in IgG4-related diseases in that they were less inflammatory and mostly non-obliterative (Figure 5). Eosinophil infiltration ( $>5$ cells/HPF) was observed in 50\% (1/2 cases) of IgG4-positive and 28\% (11/39 cases) of IgG4-negative cases. Perineural inflammation, a characteristic feature of IgG4-related diseases, was rare in both groups. Neutrophil infiltration was also observed especially around 
bile ducts erosions irrespective of IgG4-positive status. Russell bodies, which are commonly observed in IgG4-related diseases, were identified in 100\% (2/2 cases) of IgG4-positive and 54\% (21/39 cases) of IgG4-negative cases. There was no significant difference regarding peripheral portal inflammation. Significant hepatitic features were not seen in IgG4-positive cases. It was impossible to discriminate IgG4-positive from -negative PSC on H\&E-stained specimens only. Biliary dysplasia (BilIN) or carcinoma was only observed in IgG4-negative PSC.

\section{Comparison of clinical features between IgG4-positive and -negative groups}

Table 3 shows the clinical features in the 2 groups. Both IgG4-positive cases were male, 28 and 54 year. Fifteen patients had a clinical history of inflammatory bowel disease (ulcerative colitis in 12 patients and Crohn's diseases in 3 patients). Both cases with IgG4-positive PSC had ulcerative colitis.

Both IgG4-positive cases were ANA positive (1:20 and 1:40 titres), whereas the frequency of ANA in IgG4-negative case was 12/29 (31\%) (p=0.047). Except for ANA, no other significant difference was observed between the 2 groups (Table 4). Only one of the IgG4-positive PSC had slightly elevated IgG concentration (19.4 g/dL, normal range 7.0-18.6 $\mathrm{g} / \mathrm{dL}$ ). The serum IgG4 concentration was not examined in any of the patients. IgG4-related diseases like sialadenitis or retroperitoneal fibrosis were not recorded in any of the patients before and after transplantation. One IgG4-negative case was found to have chronic pancreatitis on pre-operative radiological examination. However, images were consistent with ordinary chronic pancreatitis, not autoimmune pancreatitis. 


\section{Discussion}

The results obtained in this study are summarized as follows: (1) Two PSC cases (5\%) had a high number of IgG4-positive plasma cells within the large bile duct lesion; whereas, those cells were scarce in the remaining 39 cases. The difference of IgG4-positive cell infiltration around large bile ducts between those two groups was prominent. (2) IgG4-positive cases showed histological features similar to IgG4-negative cases on H\&E-stained specimens.

(3) No clinical difference was observed between IgG4-positive and -negative PSC. The two IgG4-positive cases had inflammatory bowel disease as often the case in classical PSC and one was a young 28-year-old patient. (4) ANA seropositivity in IgG4-positive cases was significantly higher than in IgG4-negative cases.

IgG4-positive cases in this study differ from what has been reported in Japanese series of IgG4-SC in term of location and distribution of cholangitis. ${ }^{15}$ Inflammation of IgG4-SC showed a transmural distribution within the bile duct wall. ${ }^{15}$ Erosions or intraluminal proliferation of xanthogranulatous tissue was rare. ${ }^{15}$ IgG4-SC was sometimes associated with an exuberant pseudotumorous inflammatory reaction. ${ }^{15}$ In contrast, inflammation was more pronounced on the luminal side with erosions or ulcerations of the duct lining in those diagnosed as classical PSC. ${ }^{15}$ Cholangitis was also diffusely, yet unevenly distributed along the biliary tract. IgG4-related diseases may affect different organs, ${ }^{16,17}$ but inflammatory bowel disease is distinctively rare when compared to classical PSC. ${ }^{18,19}$ Finally, one of the IgG4-positive cases in this study was young. In the Japanese nationwide study $95 \%$ of patients with autoimmune pancreatitis were over 45 years. ${ }^{20}$ 
Nevertheless, the numbers of IgG4-positive plasma cells around the large ducts were prominently different between IgG4-positive and -negative cases in the present series. Immune reactions mainly mediated by Th2 and regulatory T cells (Tregs) may be involved in the pathogenesis of IgG4-related diseases. ${ }^{21}$ The expression of IL-10, an inducer of IgG4-production, is significantly higher in IgG4-related diseases than in other autoimmune disorders. ${ }^{22}$ In the 2 IgG4-positive PSC identified in this study, immune reaction involving IL-10 might occur locally around the injured bile ducts similar to allergic immune reactions in general which are mediated by Th2, Tregs, and IL-10. ${ }^{23,24}$ An alternative hypothesis which needs to be further explained is of an allergic reaction to intrinsic or extrinsic substrates present in bile rendering the marked IgG4-positive cell infiltration a superimposed phenomenon onto an otherwise classical PSC. In our experience, IgG4-positive plasma cells can be seen at the site of xanthogranulomatous inflammation in other organs, but this is not a consistent feature.

There are several limitations in this study. Because of the small number of IgG4-positive cases, it is difficult to conclude clinicopathological characteristics of IgG4-positive PSC. However, the total number of PSC cases examined in this study was not small, suggesting that significant infiltration of IgG4-positive plasma cells is a rare phenomenon in PSC. Due to the retrospective nature of this study, serum IgG4 levels could not be examined. According to a Mayo Clinic report, $9 \%$ of PSC patients have high serum IgG4 concentrations. ${ }^{13}$ In that report, patients with elevated IgG4 had higher total bilirubin, ALP, PSC Mayo risk score, and lower frequency of inflammatory bowel disease compared to patients with normal IgG4 levels. In addition, the time to liver transplantation was shorter in patients with elevated IgG4. A precise comparison of our results based primarily on pathology findings with those of the Mayo 
Clinic based essentially on clinical results is difficult, but there is a real possibility that PSC with dramatic infiltration of IgG4-positive cells in our study and patients with elevated IgG4 in the Mayo's study bear the same pathogenesis. Indeed, a recent study revealed a positive correlation between serum IgG4 concentrations and IgG4-positive plasma cell infiltrates in the explanted livers in PSC patients. ${ }^{25}$ It is well known that patients with IgG4-related disease sometimes show high serum IgG4 concentrations instead of normal or only slight elevation of total $\mathrm{IgG}$ levels. ${ }^{3}$

It should be noted that the present study was predominantly based on the large bile duct lesions. Presumably, a needle liver biopsy is not sufficient to predict the degree of infiltration of IgG4-positive plasma cells around the large bile ducts in PSC. Similarly, IgG4-positive plasma cell infiltration is usually much more significant in the hilar tissue than in peripheral portal tracts. In our experience, a needle liver biopsy is diagnostic for around $25 \%$ of patients with IgG4-SC.

Another issue is the risk of IgG4-SC to progress to cirrhosis eventually requiring liver transplantation. In a Japanese study, only one patient with IgG4-SC had the liver lesion progressed to bridging fibrosis, and no cirrhosis related to IgG4-SC was recorded. ${ }^{26}$ This may be due to the fact that IgG4-SC is commonly resected at an early stage on clinical suspicion of malignancy, thus precluding information as to how IgG4-SC might have progressed. ${ }^{15}$ IgG4-SC, possibly due to the development of pseudotumours, may mimic hilar cholangiocarcinoma more often than PSC, as suggested by Hamano et al. ${ }^{27}$ In a recent survey Ghazale A et al. found that $8 \%$ (4/53 cases) of IgG4-SC had developed liver cirrhosis or portal hypertension. ${ }^{28}$ In addition, 4 of 53 cases of IgG4-SC were not associated with pancreatitis, and all of those cases underwent 
surgical treatment for a clinical suspicion of cholangiocarcinoma. ${ }^{28}$

In conclusion, out of 41 patients transplanted for advanced PSC, we have identified 2 cases with significant tissue infiltration by IgG4-positive plasma cells, similar to so-called IgG4-SC, but in all other aspects identical to classical PSC. Investigation of both IgG4 blood levels and tissue infiltration by IgG4-positive cells is necessary for prospective assessment of patients with clinical diagnosis of PSC, and investigation of possible response to steroid treatment.

\section{Acknowledgements}

The authors thank Dr. A.S. Knisely (Institute of Liver Studies, King's College Hospital, UK) for helpful comments and suggestions. 


\section{References}

1. Björnsson E. Immunoglobulin G4-associated cholangitis. Curr Opin Gastroenterol. 2008;24:389-94.

2. Neild GH, Rodriguez-Justo M, Wall C, Connolly JO. Hyper-IgG4 disease: report and characterisation of a new disease. BMC Med. 2006;4:23.

3. Hamano H, Kawa S, Horiuchi A, et al. High serum IgG4 concentrations in patients with sclerosing pancreatitis. N Engl J Med. 2001;344:732-8.

4. Hamano H, Kawa S, Ochi Y, et al. Hydronephrosis associated with retroperitoneal fibrosis and sclerosing pancreatitis. Lancet. 2002;359:1403-4.

5. Kamisawa T, Funata N, Hayashi Y, et al. Close relationship between autoimmune pancreatitis and multifocal fibrosclerosis. Gut. 2003;52:683-7.

6. Zhang L, Notohara K, Levy MJ, Chari ST, Smyrk TC. IgG4-positive plasma cell infiltration in the diagnosis of autoimmune pancreatitis. Mod Pathol. 2007;20:23-8.

7. Kawa S, Hamano H, Umemura T, Kiyosawa K, Uehara T. Sclerosing cholangitis associated with autoimmune pancreatitis. Hepatol Res. 2007;37:S487-95.

8. Nakazawa T, Ohara H, Sano H, et al. Cholangiography can discriminate sclerosing cholangitis with autoimmune pancreatitis from primary sclerosing cholangitis. Gastrointest Endosc. 2004;60:937-44.

9. Nishino T, Oyama H, Hashimoto E, et al. Clinicopathological differentiation between sclerosing cholangitis with autoimmune pancreatitis and primary sclerosing cholangitis. $\mathbf{J}$ Gastroenterol. 2007;42:550-9.

10. Hirano K, Shiratori Y, Komatsu Y, et al. Involvement of the biliary system in autoimmune pancreatitis: a follow-up study. Clin Gastroenterol Hepatol. 2003;1:453-64.

11. Myers RN, Cooper JH, Padis N. Primary sclerosing cholangitis. Complete gross and histologic reversal after long-term steroid therapy. Am J Gastroenterol. 1970;53:527-38.

12. Gregorio GV, Portmann B, Karani J, et al. Autoimmune hepatitis/sclerosing cholangitis overlap syndrome in childhood: a 16-year prospective study. Hepatology. 2001;33:544-53.

13. Mendes FD, Jorgensen R, Keach J, et al. Elevated serum IgG4 concentration in patients with primary sclerosing cholangitis. Am J Gastroenterol. 2006;101:2070-5.

14. Hawrylowicz CM, O'Garra A. Potential role of interleukin-10-secreting regulatory T cells in 
allergy and asthma. Nat Rev Immunol. 2005;5:271-83.

15. Zen Y, Harada K, Sasaki M, et al. IgG4-related sclerosing cholangitis with and without hepatic inflammatory pseudotumor, and sclerosing pancreatitis-associated sclerosing cholangitis: do they belong to a spectrum of sclerosing pancreatitis? Am J Surg Pathol. 2004;28:1193-203.

16. Kasashima S, Zen Y, Kawashima A, et al. Inflammatory abdominal aortic aneurysm: Close relationship to IgG4-related periaortitis. Am J Surg Pathol. 2008;32:197-204.

17. Zen Y, Kitagawa S, Minato H, et al. IgG4-positive plasma cells in inflammatory pseudtumor (plasma cell granuloma) of the lung. Hum Pathol. 2005;36:710-7.

18. Ravi K, Chari ST, Vege SS, Sandborn WJ, Smyrk TC, Loftus EV Jr. Inflammatory bowel disease in the setting of autoimmune pancreatitis. Inflamm Bowel Dis. [Epub ahead of print]

19. Nakazawa T, Ohara H, Sano H, et al. Clinical differences between primary sclerosing cholangitis and sclerosing cholangitis with autoimmune pancreatitis. Pancreas 2005;30:20-5.

20. Nishimori I, Tamakoshi A, Otsuki M; Research Committee on Intractable Diseases of the Pancreas, Ministry of Health, Labour, and Welfare of Japan. Prevalence of autoimmune pancreatitis in Japan from a nationwide survey in 2002. J Gastroenterol. 2007;42:S6-8.

21. Zen Y, Fujii T, Harada K, et al. Th2 and regulatory immune reactions are increased in immunoglobin G4-related sclerosing pancreatitis and cholangitis. Hepatology. 2007;45:1538-46.

22. Jeannin P, Lecoanet S, Delneste Y, Gauchat JF, Bonnefoy JY. IgE versus IgG4 production can be differentially regulated by IL-10. J Immunol. 1998;160:3555-61.

23. Robinson DS, Larche M, Durham SR. Tregs and allergic disease. J Clin Invest. 2004;114:1389-97.

24. Romagnani S. Regulation of the development of type 2 T-helper cells in allergy. Curr Opin Immunol. 1994;6:838-46.

25. Zhang L, Lewis JT, Abraham SC, et al. IgG4+ plasma cell infiltrates in liver explants with primary sclerosing cholangitis. Am J Surg Pathol. 2010;34:88-94.

26. Umemura T, Zen Y, Hamano H, Kawa S, Nakanuma Y, Kiyosawa K. Immunoglobin G4-hepatopathy: association of immunoglobin G4-bearing plasma cells in liver with 
autoimmune pancreatitis. Hepatology. 2007;46:463-71.

27. Hamano H, Kawa S, Uehara T, et al. Immunoglobulin G4-related lymphoplasmacytic sclerosing cholangitis that mimics infiltrating hilar cholangiocarcinoma: part of a spectrum of autoimmune pancreatitis? Gastrointest Endosc. 2005;62:152-7.

28. Ghazale A, Chari ST, Zhang L, et al. Immunoglobulin G4-associated cholangitis: clinical profile and response to therapy. Gastroenterology. 2008;134;706-15. 


\section{Figure legends}

Figure 1. The number of IgG4-positive plasma cells in explanted livers for PSC. PSC cases are clearly classified into IgG4-positive (black dots) and negative (grey dots) cases, with only a few IgG4-positive plasma cells

Figure 2. Immunohistochemistry of IgG4 in a case of IgG4-negative PSC. Many plasma cells infiltrate in this field. However, only a few IgG4-positive plasma cells are observed. (original magnification $\times 400$ ).

Figure 3. Immunohistochemistry of IgG4 in a case of IgG4-positive PSC. (A and B) IgG4-positive cells were mainly observed in large portal tracts with a preferential accumulation in xanthogranulomatous areas within large bile ducts (original magnification $\times 20$, relevant $\mathrm{H} \& \mathrm{E}$ [A] and IgG4 immunostaining [B]). (C and D) Many IgG4-positive plasma cells are observed in granulation tissue within intrahepatic large bile ducts (original magnification $\times 100$, relevant $\mathrm{H} \& \mathrm{E}[\mathrm{C}]$ and $\mathrm{IgG} 4$ immunostaining $[\mathrm{D}]$ ). (E and F) IgG4 positivity is observed in the cytoplasm of plasma cells (original magnification $\times 400$, relevant $\mathrm{H} \& \mathrm{E}[\mathrm{E}]$ and IgG4 immunostaining $[\mathrm{F}])$.

Figure 4. Immunohistochemistry of IgG4 in a peripheral portal tract. Several IgG4-positive plasma cells are seen in the peripheral portal tract (original magnification $\times 200$; relevant $H \& E$ [A] and IgG4 immunostaining [B]).

Figure 5. Phlebitis in a case of IgG4-positive PSC. A vein shows partial fibrous obliteration. 
Zen - $18-$

Arrows and an asterisk indicate the muscular layer and lumen of the vein, respectively (original magnification $\times 200$., H\&E). 
Table 1

Table 1. Comparison of the numbers of IgG4-positive or total plasma cells and the ratios of IgG4-positive/total plasma cells between IgG4-positive and -negative cases (examination around the large bile duct lesions).

\begin{tabular}{lccc}
\hline & IgG4-positive* & IgG4-negative $\dagger$ & \\
& $(\mathrm{n}=2)$ & $(\mathrm{n}=39)$ & \\
\hline IgG4-positive plasma cells (per HPF) & $156 ; 134$ & $7(0-25)$ & 0.020 \\
Total plasma cells (per HPF) & $394 ; 324$ & $91(10-386)$ & 0.020 \\
IgG4-positive/total plasma cells (\%) & $40 ; 41$ & $7(0-24)$ & 0.020 \\
\hline
\end{tabular}

*, both data of the 2 cases are shown; $\dagger$, data are shown as average (range). 
Table 2

Table 2. Comparison of histological features between IgG4-positive and -negative cases.

\begin{tabular}{|c|c|c|c|}
\hline & $\begin{array}{l}\text { IgG4-positive } \\
(\mathrm{n}=2)\end{array}$ & $\begin{array}{l}\text { IgG4-negative } \\
\qquad(\mathrm{n}=39)\end{array}$ & $p$-value \\
\hline \multicolumn{4}{|l|}{ Large bile ducts } \\
\hline Inflammation (mild/moderate/severe) & $0 / 0 / 2$ & $9 / 9 / 21$ & 0.224 \\
\hline Lymph follicle & $2 / 2(100 \%)$ & $14 / 39(36 \%)$ & 0.073 \\
\hline Phlebitis & $1 / 2(50 \%)$ & $19(49 \%)$ & 0.972 \\
\hline Eosinophil inflitration $(>5$ cells/HPF) & $1 / 2(50 \%)$ & $11 / 39(28 \%)$ & 0.541 \\
\hline Russell body & $2 / 2(100 \%)$ & $21 / 39(54 \%)$ & 0.205 \\
\hline \multicolumn{4}{|l|}{ Peripheral portal tracts } \\
\hline Inflammation (mild/moderate/severe) & $1 / 1 / 0$ & $28 / 10 / 1$ & 0.541 \\
\hline
\end{tabular}


Table 3

Table 3. Comparison of clinical features between IgG4-positive and -negative cases.

\begin{tabular}{lccc} 
& IgG4-positive & IgG4-negative & \\
& $(\mathrm{n}=2)$ & $(\mathrm{n}=39)$ & \\
& 41 & 48 & \\
Average age (years) & $2 / 0$ & $22 / 17$ & 0.020 \\
Gender (male/female) & & & 0.228 \\
Inflammatory bowel disease & $2 / 2(100 \%)$ & $13 / 39(33 \%)$ & 0.059 \\
\hline
\end{tabular}


Table 4

Table 4. Comparison of laboratory data between IgG4-positive and -negative cases.

\begin{tabular}{|c|c|c|c|c|}
\hline & Normal & IgG4-positive* & IgG4-negative $\dagger$ & \\
\hline & & & $(n=39)$ & $p$-value \\
\hline Bilirubin $(\mu \mathrm{mol} / \mathrm{L})$ & $3-20$ & $507 ; 39$ & $121(441)$ & 0.565 \\
\hline Globulin (g/L) & $25-35$ & $50 ; 36$ & $39(58)$ & 0.505 \\
\hline AST (IU/L) & $10-50$ & $374 ; 133$ & $123(514)$ & 0.139 \\
\hline ALP (IU/L) & $30-130$ & $3561 ; 320$ & $664(5143)$ & 0.380 \\
\hline$\gamma$-GTP (IU/L) & $5-55$ & $156 ; 434$ & 303 (994) & 0.856 \\
\hline $\operatorname{IgG}(\mathrm{g} / \mathrm{L})$ & $7.0-18.6$ & $16.5 ; 19.4$ & $18.9(38.5)$ & 0.762 \\
\hline $\operatorname{IgA}(\mathrm{g} / \mathrm{L})$ & $0.78-4.80$ & $5.81 ; 3.48$ & $4.37(8.44)$ & 0.973 \\
\hline $\operatorname{IgM}(\mathrm{g} / \mathrm{L})$ & $0.47-2.00$ & $4.85 ; 2.37$ & $2.32(7.96)$ & 0.440 \\
\hline ANA positivity & $<20$ titers & $2 / 2(100 \%)$ & $12 / 39(31 \%)$ & 0.047 \\
\hline ANCA positivity & $<7.0 \mathrm{U} / \mathrm{mL}$ & $0 / 2(0 \%)$ & $6 / 19(32 \% \ddagger)$ & 0.359 \\
\hline
\end{tabular}

$*$, both data of the 2 cases are shown; $\dagger$, data are shown as average (maximum); $\$$, available in 19 cases only. 


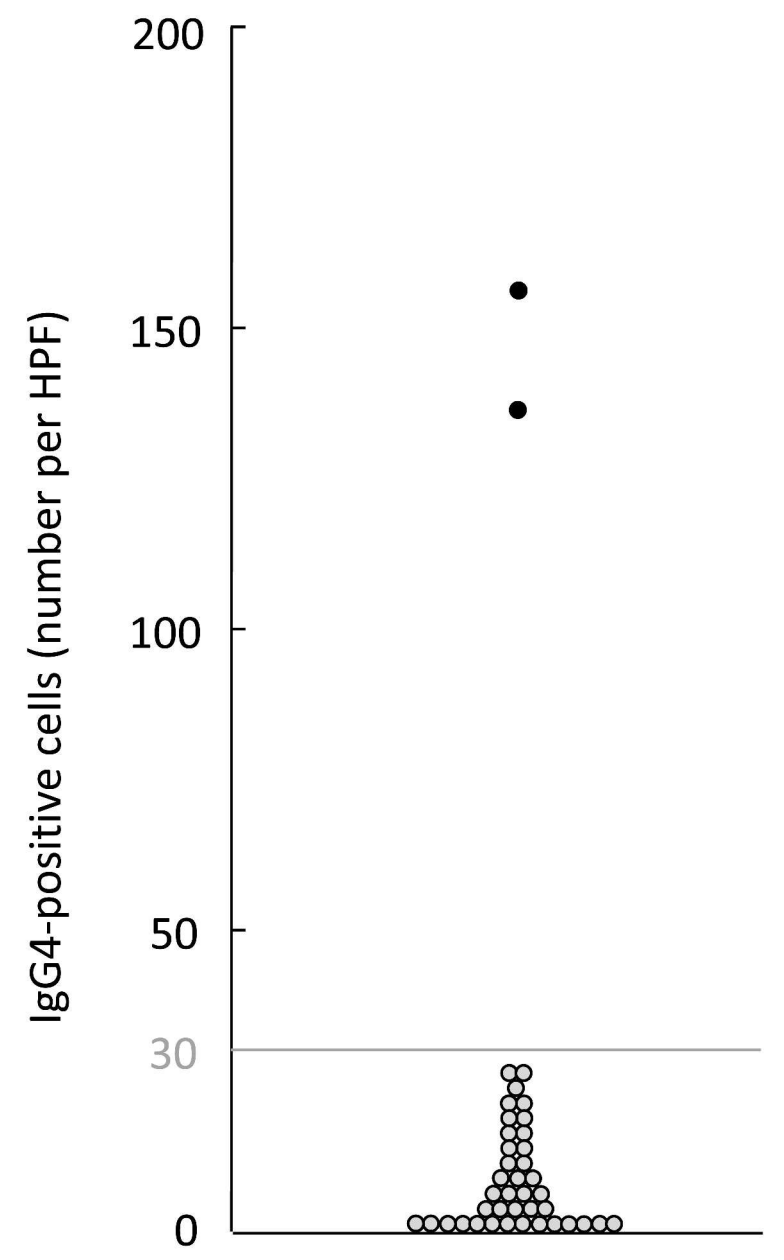

Figure 1

Figure 1. The number of IgG4-positive plasma cells in explanted livers for PSC. PSC cases are clearly classified into IgG4-positive (black dots) and negative (gray dots) cases. However, only a few IgG4-positive plasma cells are observed. (original magnification $\times 200$ ). $139 \times 206 \mathrm{~mm}(600 \times 600 \mathrm{DPI})$ 


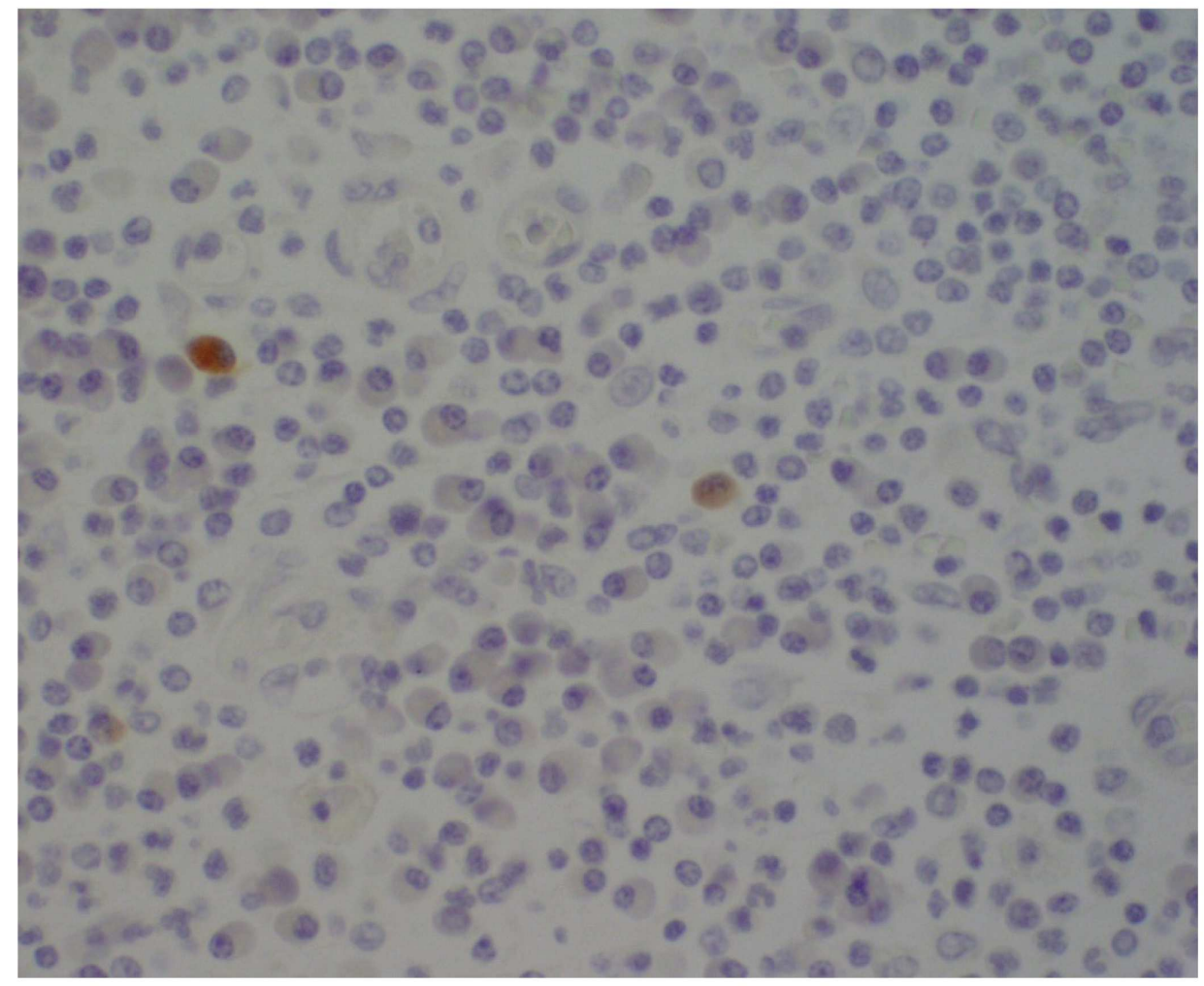

Figure 2

Figure 2. Immunohistochemistry of IgG4 in a case of IgG4-negative PSC. Many plasma cells infiltrate in this field. However, only a few IgG4-positive plasma cells are observed. (original magnification $\times 400)$.

$112 \times 104 \mathrm{~mm}(500 \times 500 \mathrm{DPI})$ 

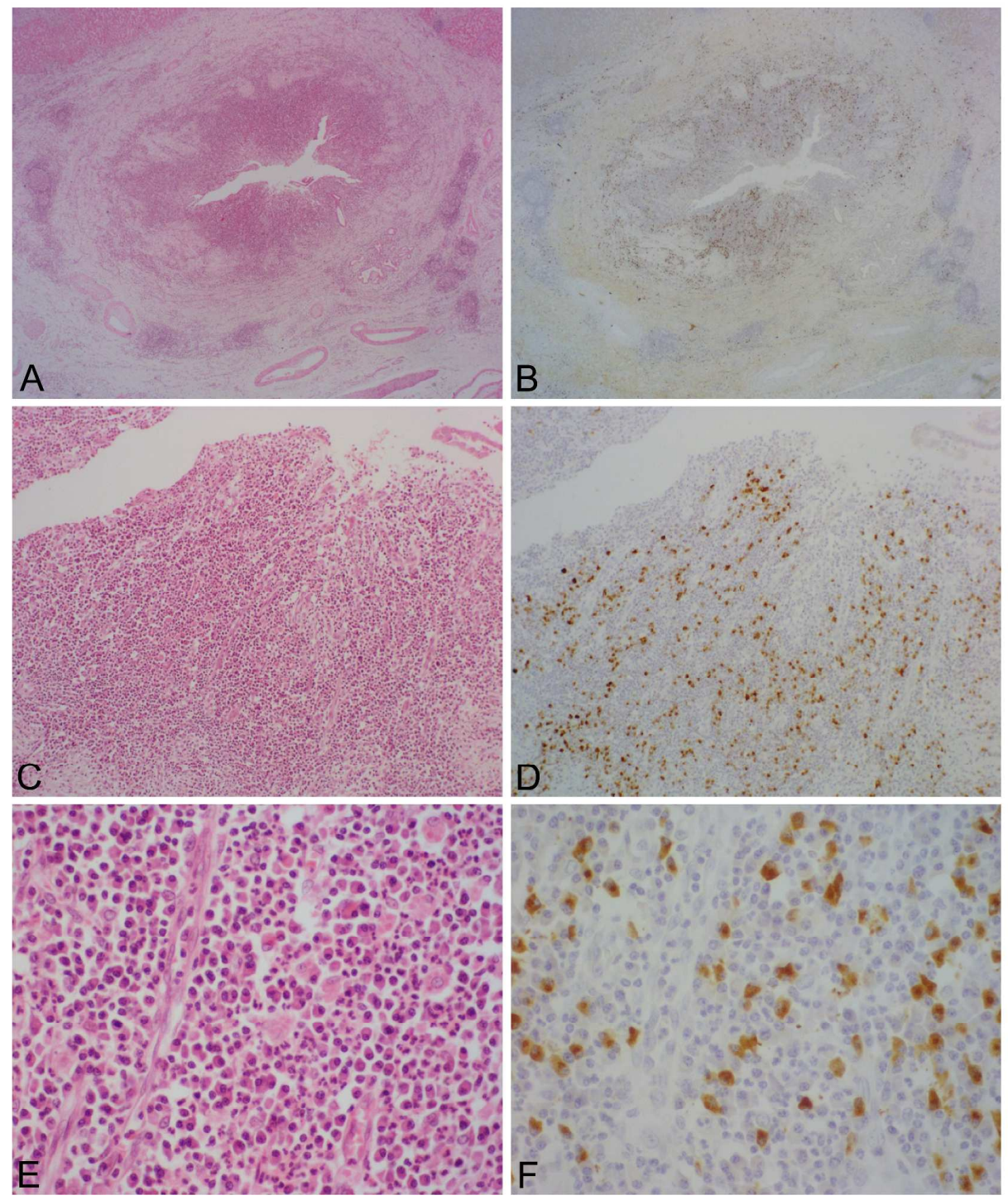

Figure 3

Figure 3. Immunohistochemistry of IgG4 in a case of IgG4-positive PSC. (A and B) IgG4-positive cells were mainly observed in large portal tracts with a preferential accumulation in xanthogranulomatous areas within large bile ducts (original magnification $\times 20$, relevant H\&E [A] and IgG4 immunostaining [B]). (C and D) Many IgG4-positive plasma cells are observed in granulation tissue within intrahepatic large bile ducts (original magnification $\times 100$, relevant H\&E [C] and IgG4 immunostaining [D]). (E and F) IgG4 positivity is observed in the cytoplasm of plasma cells (original magnification $\times 400$, relevant $\mathrm{H} \& \mathrm{E}[\mathrm{E}]$ and IgG4 immunostaining $[\mathrm{F}]$ ). $220 \times 276 \mathrm{~mm}(400 \times 400$ DPI $)$ 

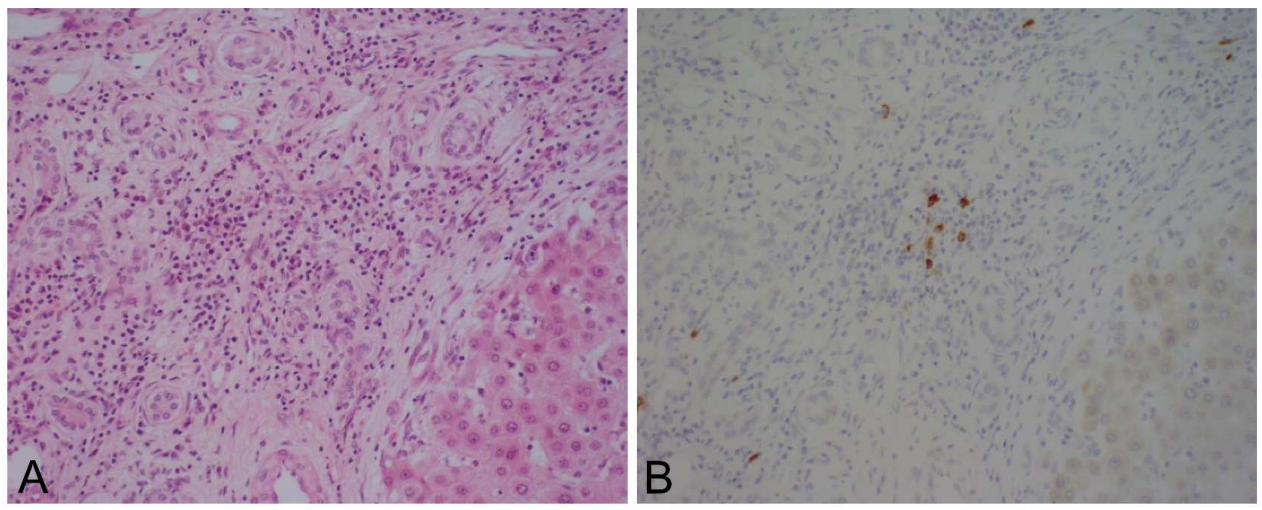

Figure 4

Figure 4. Immunohistochemistry of IgG4 in a peripheral portal tract. Several IgG4-positive plasma cells are seen in the peripheral portal tract (original magnification $\times 200$; relevant H\&E $[A]$ and IgG4 immunostaining $[B])$.

$220 \times 113 \mathrm{~mm}(400 \times 400 \mathrm{DPI})$ 


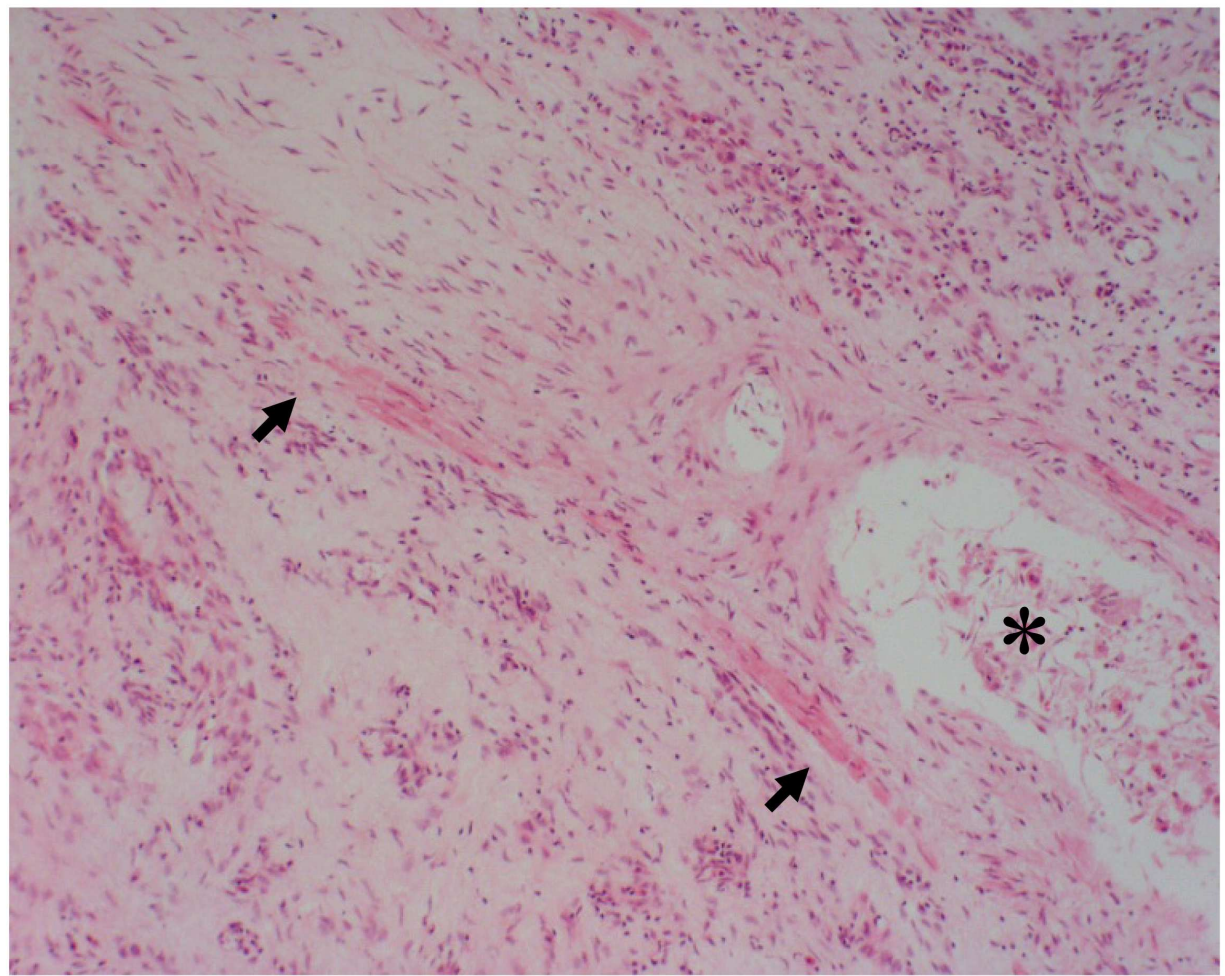

Figure 5

Figure 5. Phlebitis in a case of IgG4-positive PSC. A vein shows partial fibrous obliteration. Arrows and an asterisk indicate the muscular layer and lumen of the vein, respectively (original magnification $\times 200$., $\mathrm{H} \& \mathrm{E})$. $126 \times 115 \mathrm{~mm}(500 \times 500 \mathrm{DPI})$ 